\title{
Biomarker Identification of Tear Fluid
}

\section{Fumio Tsuji* and Kouichi Kawazu}

Ophthalmic Research and Development Center, Santen Pharmaceutical Co. Ltd., 8916-16 Takayama-cho, Ikomashi, Nara 630-0101, Japan

\begin{abstract}
While some potential biomarkers for ocular diseases have been reported, it is difficult to select a single biomarker that is most important in each ocular disease. After reviewing multiple biomarker studies conducted on small sample subgroups, we concluded that newer analysis techniques may result in different and more specific findings. While progress has been made in developing various omics studies, studies comparing tears of normal and diseased eyes are still lacking. Preliminary omics studies suggest the importance of further studies aimed at identifying potential ocular-associated lipid, non-lipid/protein, and protein biomarkers. In addition, combining potential biomarkers might be a good strategy for the diagnosis and assessment of ocular diseases.
\end{abstract}

Keywords: Biomarker of tear fluid; Ocular disease; Omics study

\section{Introduction}

Tear fluid serves several functions. The primary role of tear fluid is to provide the cornea with a surface of high optical quality and maintain the well-being of the corneal and conjunctival epithelium. The secondary function of tear fluid is to lubricate the eyelids during blinking. Furthermore, tear fluid is known to have bactericidal properties [1]. Performing these functions requires a complex multilayer film containing proteins, enzymes, lipids, and salts produced by more than one glandular system. Clinical evidence suggests that relatively minor changes in concentrations and composition of elements within the tear fluid can profoundly affect tear film stability and ocular health [2-4].

A number of chronic diseases of the ocular surface produce symptoms known collectively as chronic ocular discomfort. Blepharitis, allergic eye disease, hyposecretive dry eye, and conjunctivochalasis are among the most frequent ocular surface disorders, and it has been demonstrated that inflammation plays an essential role in the pathogenesis of these conditions. However, we currently have little definitive information regarding which specific tear fluid components change in response to these diseases; we also do not know the concentrations of these components that can induce physiological changes in the tear film. In this paper, we review the data related to biomarker identification of tear fluid.

\section{Proteomic analysis of tear fluid}

The major tear proteins include lysozyme, lactoferrin, secretory immune-globulin A, lipocalin, albumin, and lipophilin; the protein content in tears reportedly varies between 6 and $10 \mathrm{mg} / \mathrm{mL}[5,6]$. Up- or down regulation of tear proteins can be indicative of the underlying pathology [7-11]. Qualitative and quantitative techniques that have been applied to the study of the tear proteome include gel electrophoresis [12], enzyme-linked immunosorbent assay, and highperformance liquid chromatography [13]. More recently, analytical methods with high sensitivity and resolution have been used in detailed studies of changes in tear composition following injury or disease. These methods, which have been used to map tear protein profiles, include several mass spectrometry (MS) technologies, such as matrix assisted laser desorption ionization-time of flight (MALDITOF), surface-enhanced laser desorption ionization-TOF (SELDITOF), linear ion trap-Fourier transform, and liquid chromatography coupled with electrospray ionization (LC/MS) $[10,11,14-16]$ as well as multiplex bead analysis systems [17]. The wide range in the number of proteins detected and identified in tears results both from differing sensitivities of the MS methods used by various investigators and the high dynamic range of tear fluid, a small group of proteins (lysozyme, lipocalin, and lactoferrin) account for $70 \%-80 \%$ of the protein content [18], which may make detection of less abundant proteins difficult without prefractionation of samples. The results of MS studies have revealed a common set of 30-40 proteins that are consistently identified independent of the sampling and MS detection method. While progress has been made in developing proteomic baseline studies of tear proteins, there have been few studies that compare normal and diseased tears.

While the meibomian gland has been primarily viewed as a lipid factory with a primary purpose of producing and excreting lipids onto the ocular surface, a recent study reported the identification of more than 90 proteins in human meibomian gland secretion [19]. The identified proteins included cellular proteins, such as cytoplasmic, mitochondrial, nuclear, and membrane proteins, which would be expected because of the holocrine nature of the meibomian gland Table 1. Unexpectedly, a number of lipid-binding proteins were also reported, such as potential phospholipid-transporting ATPase IK, and lipocalin 1, which binds to a number of lipophilic ligands.

Proteins in the tear fluid may play crucial roles in maintaining eye health. Perturbation of proteins in the tear fluid may lead to the development of disease, and thus, tear fluid proteins might be interesting targets for disease diagnosis and further functional characterization.

\section{Lipidomic analysis of tear fluid}

The lipid layer of the tear film is a complex mixture of triglycerides, free fatty acids, diesters, cholesterol and wax esters, free cholesterol, hydrocarbons, and polar lipids produced primarily by the meibomian gland [20,21]. A three-layered structure (lipid layer, aqueous-mucin layer, and glycocalyx layer) is the generally accepted model of the

*Corresponding author: Fumio Tsuji, Ophthalmic Research and Development Center, Santen Pharmaceutical Co. Ltd., 8916-16 Takayama-cho, Ikoma-shi, Nara 630-0101, Japan, Tel: +81-743-79 4552; Fax: +81-743-79-4518, E-mail: fumio.tsuji@santen.co.jp

Received December 12, 2011; Accepted January 21, 2012; Published January 23, 2012

Citation: Tsuji F, Kawazu K (2012)Biomarker Identification of Tear Fluid. Metabolomics 2:105. doi:10.4172/2153-0769.1000105

Copyright: (c) 2012 Tsuji F, et al. This is an open-access article distributed under the terms of the Creative Commons Attribution License, which permits unrestricted use, distribution, and reproduction in any medium, provided the original author and source are credited. 
compositional make-up of the tear film [21]. Current tear film models suggest that a chemically stable, lamellar layer of polar phospholipids lies anterior to the aqueous fluid and binds the nonpolar meibomian oil to the aqueous layer [22]. The presence of this polar phospholipid interface is thought to be critical to the spreading of the nonpolar lipid film over the aqueous layer. The polar phosphorylated lipids of the inner layer act as surfactants and as an anchoring layer at the lipidaqueous interface, whereas the outer, nonpolar layer primarily retards evaporation of the aqueous layer from the tear film. The instability of the outer lipid layer of the tear film, due to changes in the polar lipid concentration, has been identified as a potential factor in the development of dry eye syndrome [23,24].

Analysis of the meibum and tear lipids has also been hampered by a lack of sensitive analytical methods and the need for pooled samples and extensive sample manipulation before analysis (tags or derivatization), similar to tear proteins. Despite the difficulties, the chemical composition of human meibomian gland liquid secretions has been characterized by pico-nuclear magnetic resonance [25] and thin-layer chromatography [26]. Fatty acid fragment profiles have been obtained using LC/MS [27].

\section{Ocular disease and biomarker research}

An important ongoing and future focus of tear- and meibum filmassociated biomolecule research is the measurement and identification of disease state biomarkers [28]. To date, there are a number of tear fluid- and meibum-associated lipids and proteins that have been identified as possible disease-related biomarkers. The new wave of "omics" methods, such as proteomics, metabolomics, glycomics, and lipidomics, have made the identification of disease state markers in meibomian lipid and tear fluid more achievable. Development of bioinformatics databases associated with mass spectrometry and genetic sequencing have further advanced these investigative techniques. Once identified, biomarkers can be used for clinical diagnostics and early detection of dry eye diseases, such as keratoconjunctivitis siccaassociated dry eye (evaporative keratoconjunctivitis sicca), meibomian gland disease, Sjögren syndrome, blepharitis, androgen deficiency, age- related dry eye, and lacrimal gland dysfunctions. Proper and specific diagnosis allows medical intervention that may substantially influence relative success of early treatments and subsequent cures.

\section{Biomarkers for corneal wounding}

Tears contain a complex mixture of proteins and while changes in some peptides have been found, the fate of most of the more than one hundred tear proteins remains unknown during corneal wound healing. Such potential changes in tear proteins are important because they play important roles in regulating epithelial migration, proliferation and differentiation, cell-to-cell and cell-to-matrix interactions, stromaextracellular matrix production, inflammation, scar formation, and protection against pathogens. Previous studies have identified some tear proteins that may participate in the corneal wound-healing cascade. For example, fibronectin [29], a glycoprotein present in plasma and the extracellular matrix, has a role in epithelial cell migration and is a temporary substrate for cells migrating on the corneal surface. Other extracellular matrix related proteins released in tear fluids, such as plasminogen activator [30] and matrix metalloproteinases (MMP-8 and MMP-14) [31], also have been suggested to play roles in the wound healing process. Neuropeptides, such as substance P (SP) [32] and calcitonin gene-related peptide (CGRP) [33], are important molecules because of their roles in the neurogenic phase of a wound response, which results in the breakdown of the blood-ocular barrier and allows large numbers of neutrophils to access the tears. A number of growth factors and cytokines, including epidermal growth factor (EGF) [34], transforming growth factor- $\beta$ [35], vascular endothelial growth factor [35], platelet-derived growth factor-BB [36], hepatocyte growth factor [37], basic fibroblast growth factor [38], tumor necrosis factor- $\alpha$ [39], and interleukin (IL)-6 [40], have been found in tears and may modulate wound healing by stimulating epithelial growth, whereas others may trigger epithelial cell apoptosis. Potential tear protein biomarkers for corneal wounding have been observed in rabbit and human tear protein studies utilizing electrospray ionization (ESI)/MS or SELDITOF-MS Protein Chips Table 2 and included 1) an eight-fold increase in lysozyme [14]; 2) upregulation of neutrophil defensins NP-1 and

\begin{tabular}{|l|l|}
\hline Protein & Function \\
\hline a2 Macroglobulin receptor & Proteinase and growth factor regulation; lipoprotein metabolism \\
\hline IgA $\alpha$ chain & Mucosal immunity \\
\hline Farnesoid X activated receptor & Cholesterol homeostasis modulation \\
\hline Interferon regulatory factor 3 & Innate immune system's response to viral infection \\
\hline Lacritin precursor & Secretion and renewal of lacrimal and ocular surface epithelia \\
\hline Lactotransferrin (lactoferrin) & Anti-inflammatory and/or anti-microbial function \\
\hline Lipocalin 1 & Physiological scavenger of potentially harmful lipophilic molecules; the maintenance of tear film stability \\
\hline Lysozyme C precursor & Anti-inflammatory and/or anti-microbial function \\
\hline Potential phospholipid transporting ATPase IK & Phospholipid transfer \\
\hline Somatostatin receptor type 4 & Inhibition of adenylate cyclase; activation of both arachidonate release and the mitogen activated protein kinase cascade \\
\hline High affinity IgE receptor $\beta$ subunit & Binding to the Fc region of the IgE receptor; initiation of the allergic response \\
\hline TrkC tyrosine kinase & The receptor for neurotrophin-3 \\
\hline
\end{tabular}

Table 1: Analysis of proteins in human meibomian gland secretions $[19,57,58]$.

\begin{tabular}{|l|l|l|l|l|l|}
\hline Biomarker & Omics & Analytical Method & Sample Source & Marker type \\
\hline Lysozyme & Proteomics & HPLC-ESI/MS & Tear (Rabbit) & Corneal wounding & Up (8) \\
\hline Neutrophil defensins NP-1 and NP-2 & Proteomic & SELDI-TOF-MS Protein Chip & Tear (Rabbit) & Corneal wounding & Up (6.4-10.2) \\
\hline A-defensins (HNP-1, HNP-2, and HNP-3) & Proteomic & SELDI-TOF-MS Protein Chip & Tear (Human) & Ocular surface surgery & Up (>10) \\
\hline
\end{tabular}

Ratio: (diseased eye)/(normal eye)

HPLC-ESI/MS: high-performance liquid chromatography-electrospray ionization/mass spectrometry, SELDI-TOF: surface-enhanced laser desorption ionization-time of flight

Table 2: Tear- and meibum-associated potential protein biomarkers tentatively identified for corneal wounding in animal models and human subpopulations [28]. 
NP-2 [41]; and 3) upregulation of human a-defensins, HNP-1, HNP-2, and HNP-3 [42].

\section{Biomarkers for dry eye}

The number of patients with dry eye is rapidly increasing. Patients with dry eye typically report discomfort, burning, irritation, photophobia, and blurred vision and have an elevated risk of corneal infection and irreversible tissue damage [43]. Several potential tear biomarkers for dry eye syndrome have been identified Table 3 and Table 4. Differential regulation of lactoferrin (down), EGF (down), and aquaporin 5 (up) were found to be associated with a variety of dry eye syndromes (non-Sjögren, Sjögren, and Stevens-Johnson) [9]. Seven tear biomarkers were found to be generally associated with dry eye syndrome: up-regulation of the C-terminal fragment of alpha-1antitrypsin and calgranulin $\mathrm{A}$, and downregulation of nasopharyngeal carcinoma-associated proline-rich protein, proline-rich protein 4 , and proline-rich protein 3 [10]. In another study, up-regulation of 6 proteins, $\alpha$-enolase; $\alpha$-1-acid glycoprotein 1; S100 A8 (calgranulin
A); S100 A9 (calgranulin B); S100 A4; and S100 A11 (calgizzarin), and down-regulation of 4 proteins, prolactin-inducible protein (PIP); lipocalin-1; lactoferrin; and lysozyme, [44] was associated with dry eye syndrome. In addition, dry eye tear protein exhibited differential expression of proteins as observed in the 25-35 kDa regions. One of the proteins with significantly reduced levels was proline-rich protein 4 [45]. Calgranulin A and proline-rich protein 4 were identified in the reports of both groups. Ten unidentified proteins were found to be differentially regulated in Sjögren syndrome. These ten proteins were only identifiable by their masses; seven proteins were downregulated $(2094,2743,14191,14702,16429,17453$, and $17792 \mathrm{~m} / \mathrm{z})$ and three were upregulated $(3483,4972$, and $10860 \mathrm{~m} / \mathrm{z})$ [7].

Polar and nonpolar lipid expression changes were observed in the tears of a surgically induced dry eye rabbit model. In this model, the lacrimal and Harderian glands were removed from one eye to produce a dry eye condition, while the contralateral eye was kept normal as a control, and the tear lipids were determined by ESI/QhQ/MS [46] and

\begin{tabular}{|c|c|c|c|c|c|c|}
\hline Biomarker & Omics & Analytical Method & Sample Source & Marker type & Regulation (ratio) & Ref \\
\hline $\begin{array}{l}\text { Lipophilin } \\
\text { Cystatin/lysozyme } \\
\text { Lipophilin CL } \\
\text { Lipocalin } \\
\text { Unidentified } \\
\beta-2 \text { Microglobulin } \\
\text { Heterodimer of lipophilins A and C } \\
\text { Apolipoprotein D monomer }\end{array}$ & Proteomics & $\begin{array}{l}\text { 1-D SDS-PAGE } \\
\text { MALDI-TOF/MS } \\
\text { ESI-QhQ/MS }\end{array}$ & Tear (Rabbit) & Surgically induced dry eye & $\begin{array}{l}\text { Up }(2.1) \\
\text { Up }(2.8) \\
\text { Up }(1.4) \\
\text { Up }(1.1) \\
\text { Up }(1.3) \\
\text { Down }(0.4) \\
\text { Down }(0.5) \\
\text { Down }(0.7)\end{array}$ & [59] \\
\hline $\begin{array}{l}\text { Lactoferrin } \\
\text { EGF } \\
\text { AQP5 }\end{array}$ & Proteomics & ELISA & Tear (Human) & $\begin{array}{l}\text { Dry eye (non-Sjögren, Sjögren \& } \\
\text { Stevens-Johnson Syndrome) }\end{array}$ & $\begin{array}{l}\text { Down (0.06-0.34) } \\
\text { Down (0.06-0.45) } \\
\text { Up (4.0; Sjögren } \\
\text { only) }\end{array}$ & [9] \\
\hline $\begin{array}{l}\text { a-1-antitrypsin, C-terminal fragment } \\
\text { Calgranulin A } \\
\text { Unidentified } \\
\text { Nasopharyngeal carcinoma-associated } \\
\text { proline-rich protein } \\
\text { Proline-rich protein } 4 \\
\text { Proline-rich protein } 3 \\
\text { Unidentified }\end{array}$ & Proteomics & $\begin{array}{l}\text { SELDI-TOF-MS (Shirmer tear } \\
\text { collection) }\end{array}$ & Tear (Human) & Dry eye & $\begin{array}{l}\text { Up (1.8) } \\
\text { Up (3.0) } \\
\text { Up (13.9) } \\
\text { Down }(0.37) \\
\\
\text { Down (0.32) } \\
\text { Down }(0.40) \\
\text { Down }(0.39)\end{array}$ & {$[10]$} \\
\hline Ten proteins ( $\mathrm{m} / \mathrm{z}$ data only) & Proteomic & $\begin{array}{l}\text { SELDI-TOF-MS (Shirmer tear } \\
\text { collection) }\end{array}$ & Tear (Human) & Sjögren syndrome & $\begin{array}{l}\text { 3-Up } \\
\text { 7-Down }\end{array}$ & [7] \\
\hline $\begin{array}{l}\text { a-enolase } \\
\text { a-1-acid glycoprotein } 1 \\
\text { S100 A8 Calgranulin A } \\
\text { S100 A9 Calgranulin B } \\
\text { S100 A11 Calgizzarin } \\
\text { S100 A4 Calcium-Binding protein } \\
\text { Prolactin-inducible protein } \\
\text { Lipocalin-1 } \\
\text { Lactoferrin } \\
\text { Lysozyme C }\end{array}$ & Proteomic & iTRAQ ESI-MS/MS & Tear (Human) & Dry eye & $\begin{array}{l}\text { Up (1.7) } \\
\text { Up (2.4) } \\
\text { Up (1.4) } \\
\text { Up (1.4) } \\
\text { Up (1.7) } \\
\text { Up (2.3) } \\
\\
\text { Down (0.59) } \\
\text { Down (0.76) } \\
\text { Down (0.79) } \\
\text { Down (0.70) }\end{array}$ & {$[44]$} \\
\hline Metalloproteinase-9 & Proteomic & ELISA & Tear (Human) & Dry eye & Up (4.2-45.4) & {$[60]$} \\
\hline $\begin{array}{l}\text { EGF } \\
\text { Fractalkine/CX3CL1 } \\
\text { IL-1Ra } \\
\text { IP-10/CXCL10 } \\
\text { VEGF }\end{array}$ & Proteomic & Multiplex bead analysis & Tear (Human) & Dry eye & $\begin{array}{l}\text { Up }(>10) \\
\operatorname{Up}(>10) \\
\operatorname{Up}(10) \\
\operatorname{Up}(10) \\
\operatorname{Up}(<10)\end{array}$ & {$[17]$} \\
\hline Proline-rich 4 protein & Proteomic & 2-D electrophoretic analysis & Tear (Human) & Dry eye & Down (ND) & {$[46]$} \\
\hline
\end{tabular}

Ratio: (diseased eye)/(normal eye)

ND: not determined, 1-D-SDS-PAGE: one-dimensional-sodium dodecyl sulfate polyacrylamide gel electrophoresis, MALDI-TOF/MS: matrix assisted laser desorption ionization-time of flight/mass spectrometry, SELDI-TOF: surface-enhanced laser desorption ionization-time of flight, ESI-QhQ: electrospray ionization-Quadrupolehexapole-quadrupole, ELISA: enzyme-linked immunosorbent assay, iTRAQ: isobaric tag for relative and absolute quantitation

Table 3: Tear- and meibum-associated potential protein biomarkers tentatively identified for dry eye syndrome in animal models and human subpopulations [28] 


\begin{tabular}{|c|c|c|c|c|c|c|}
\hline Biomarker & Omics & Analytical Method & Sample Source & Marker type & Regulation (ratio) & Ref. \\
\hline $\begin{array}{l}\text { Free glycerol } \\
\text { Glycerylisoprene acetals } \\
\text { Monopalmitin } \\
\text { Monostearin } \\
\text { 1,3-Dipalmitin } \\
\text { 1-Stearin-3-palmitin } \\
\text { 1,3-Distearin } \\
\text { Tristearin }\end{array}$ & Lipidomic & ESI-QhQ/MS & Tear (Rabbit) & Dry eye & $\begin{array}{l}\text { Up (1.6) } \\
\text { Up (2.4-2.5) } \\
\text { Up (1.5) } \\
\operatorname{Up~(1.6)~} \\
\operatorname{Up~(1.5)~} \\
\operatorname{Up~(1.4)~} \\
\operatorname{Up~(1.4)~} \\
\text { Up (1.4) }\end{array}$ & [47] \\
\hline $\begin{array}{l}\text { Pyrophosphate sphingomyelin } \\
\text { Phosphatidylserine }\end{array}$ & Lipidomic & MALDI-TOF/MS & Tear (Rabbit) & Dry eye & $\begin{array}{l}\text { Up (ND) } \\
\text { Up (ND) }\end{array}$ & [48] \\
\hline $\begin{array}{l}\text { Polar and neural lipids ( } \mathrm{m} / \mathrm{z} \text { data } \\
\text { only) }\end{array}$ & Lipidomic & HPLC/MS & Meibum (Human) & Age-related dry eye & Various changes (ND) & [49] \\
\hline Diadenosine polyphosphates & Metabonomic & $\begin{array}{l}\text { HPLC (Shirmer tear } \\
\text { collection) }\end{array}$ & Tear (Human) & Dry eye & $\begin{array}{l}\text { Up (100-345; with low tear } \\
\text { secretion subjects) }\end{array}$ & [50] \\
\hline Tear osmolarity & - & Osmometer & Tear (Human) & Dry eye & Up (ND) & [51] \\
\hline
\end{tabular}

Ratio: (diseased eye)/(normal eye)

ND: not determined, ESI-QhQ/MS: electrospray ionization-quadrupole-hexapole-quadrupole/mass spectrometry, MALDI-TOF: matrix assisted laser desorption ionizationtime of flight, HPLC: high-performance liquid chromatography

Table 4: Tear- and meibum-associated potential lipid and non-lipid/protein biomarkers tentatively identified for dry eye in animal models and human subpopulations [28].

\begin{tabular}{|c|c|c|c|c|c|c|}
\hline Biomarker & Omics & Analytical Method & Sample Source & Marker type & Regulation (ratio) & Ref. \\
\hline $\begin{array}{l}\text { Serum albumin precursor } \\
\text { Ig } \mathrm{k} \text { chain-VIII } \\
\text { Pyruvate kinase } \\
\text { a-1-antitrypsin } \\
\text { Prolactin-inducible protein } \\
\text { Cystatin SA-III } \\
\text { Lacritin precursor } \\
\text { Lysozyme } \\
\text { Unidentified }\end{array}$ & Proteomic & $\begin{array}{l}\text { 2-D SDS-PAGE } \\
\text { ESI-QTOF/MS }\end{array}$ & Tear (Human) & Blepharitis & $\begin{array}{l}\text { Down (0.5) } \\
\text { Down (0.5) } \\
\text { Down (0.5) } \\
\text { Down (0.5) } \\
\text { Down (0.5) } \\
\\
\text { Down (0.5) } \\
\text { Down (0.5) } \\
\text { Down (0.5) } \\
\text { Down (0.5) }\end{array}$ & [8] \\
\hline $\begin{array}{l}\text { IL-6 } \\
\text { Pro-MMP-9 }\end{array}$ & Proteomic & ELISA & Tear (Human) & Blepharitis & $\begin{array}{l}\text { Up (2.0) } \\
\text { Up (2.5) }\end{array}$ & [52] \\
\hline $\begin{array}{l}\text { Cholesterol } \\
\text { Ceramides }\end{array}$ & Lipidomic & TLC & Meibum (Rabbit) & $\begin{array}{l}\text { Meibomian gland } \\
\text { deficiency }\end{array}$ & $\begin{array}{l}\text { Up (2) } \\
\text { Up (2) }\end{array}$ & [53] \\
\hline $\begin{array}{l}\text { Phosphoethanolamine } \\
\text { Sphingomyelin }\end{array}$ & Lipidomic & $\begin{array}{l}\text { TLC/HPLC } \\
\text { Cl-GC/MS }\end{array}$ & Meibum (Human) & $\begin{array}{l}\text { Chronic blepharitis } \\
\text { with KCS }\end{array}$ & $\begin{array}{l}\text { Down }(0.28) \\
\text { Down }(0.51)\end{array}$ & [23] \\
\hline $\begin{array}{l}\text { Phase transition temperature } \\
\text { Hydrocarbon chain order } \\
\text { Lipid-lipid interaction enthalpy }\end{array}$ & Lipidomic & IR & Meibum (Human) & $\begin{array}{l}\text { Meibomian gland } \\
\text { dysfunction }\end{array}$ & $\begin{array}{l}\text { Up (ND) } \\
\text { Up (1.3) } \\
\text { Up (1.3) }\end{array}$ & [54] \\
\hline
\end{tabular}

KCS: keratoconjunctivitis sicca

Ratio: (diseased eye)/(normal eye)

ND: not determined, ESI-QTOF/MS: electrospray ionization-quadrupole time-of-flight mass spectrometry /mass spectrometry, 2-D-SDS-PAGE: two-dimensional-sodium dodecyl sulfate polyacrylamide gel electrophoresis, ELISA: enzyme-linked immunosorbent assay, TLC/HPLC: thin-layer chromatography/high-performance liquid chromatography, Cl-GC: chemical ionization-gas chromatography

Table 5: Tear- and meibum-associated potential protein and lipid biomarkers tentatively identified for blepharitis and meibomian gland dysfunction in animal models and human subpopulations [28].

MALDI-TOF [47]. There was a significant increase in the concentrations of three types of sphingomyelin lipids and a phosphatidylserine lipid in dry eye tears compared with normal tears. The presence of different sphingomyelin and phosphatidylserine species in dry eye tears suggests that the meibomian gland might compensate to stabilize the tear film in the absence of lacrimal and Harderian gland secretions. In addition, Sullivan et al. [48] described the effect that complete androgen insensitivity syndrome and aging have on the polar and neutral lipid fractions of patient meibum samples. The meibum obtained from women with complete androgen insensitivity syndrome exhibited significant differences in expression levels of nonpolar lipids, including wax and cholesterol esters. The polar lipid fractions also exhibited differences associated with the complete androgen insensitivity syndrome condition that included certain phosphatidylcholine and phosphatidylethanolamine species. Finally, significant differences were observed in the nonpolar and polar lipid profiles associated with aging, suggesting that alterations in the lipid might be related to the agerelated increase of observed cases of dry eye syndrome.

In a human tear biomarker study, diadenosine polyphosphates were found to be increased 100-345-fold in patients with reduced tear secretion and symptomatic dry eye [49]. The observed increase in diadenosine polyphosphates could thus be used as an objective biomarker in the initial observance of dry eye condition. In addition, tear osmolarity correlates with dry eye severity, and therefore could provide a biomarker for disease severity [50]. 


\begin{tabular}{|c|c|c|c|c|c|c|}
\hline Biomarker & Omics & Analytical Method & Sample Source & Marker type & Regulation & Ref. \\
\hline $\begin{array}{l}\text { Protein S100-A8 } \\
\text { Protein S100-A9 } \\
\text { Protein S100-A4 } \\
\text { GTP-bunding protein } 2 \\
\text { L-lactate dehydrogenase A like 6B } \\
\text { Fatty acid-binding protein } \\
\text { Keratin type I cytoskeletal } 10 \\
\text { Glutathione S-transferase P } \\
\text { Peroxiredoxin-1 } \\
\text { Peroxiredoxin-5 } \\
\text { Cullin-4B + glyceraldehyde 3-phosphate dehydrogenase }\end{array}$ & Proteomic & $\begin{array}{l}\text { 2-D SDS-PAGE } \\
\text { MALDI-TOF/MS }\end{array}$ & Tear (Human) & Conjunctivochalasis & $\begin{array}{l}\text { Up }(2.44) \\
\text { Up }(1.71) \\
\text { Up (2.82) } \\
\text { Up }(1.95) \\
\text { Up }(2.32) \\
\text { Up }(2.01) \\
\text { Up }(1.81) \\
\text { Up }(2.27) \\
\text { Up }(1.79) \\
\text { Up }(1.92) \\
\text { Up }(1.96)\end{array}$ & {$[56]$} \\
\hline 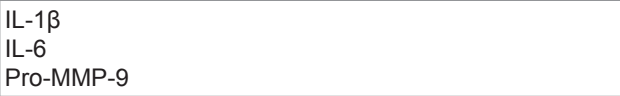 & Proteomic & ELISA & Tear (Human) & Conjunctivochalasis & $\begin{array}{l}\text { Up }(4.2) \\
\text { Up (6.3) } \\
\text { Up (5.3) }\end{array}$ & [52] \\
\hline
\end{tabular}

2-D-SDS-PAGE: two-dimensional-sodium dodecyl sulfate polyacrylamide gel electrophoresis, MALDI-TOF/MS: matrix assisted laser desorption ionization-time of flight/ mass spectrometry, ELISA: enzyme-linked immunosorbent assay

Table 6: Tear- and meibum-associated potential protein and lipid biomarkers tentatively identified for conjunctivochalasis in animal models.

\section{Biomarkers for blepharitis}

Chronic blepharitis is one of the most common eye diseases and is an extremely complex condition that manifests with several different and overlapping signs and symptoms [51]. Symptoms can include crusting of the lid margins, itching and burning eyelids as well as signs of eyelid inflammation, and associated conjunctival and corneal changes. Several investigators have discovered potential tear biomarkers for blepharitis Table 5. Down regulation of nine proteins (serum albumin precursor, $\alpha-1$ antitrypsin, lacritin precursor, lysozyme, Ig- $\kappa$ chain VIII, prolactin inducible protein (PIP/GCDFP-15), cystatin SA-III, pyruvate kinase, and an unnamed protein) has been found to be associated with blepharitis [8]. Moreover, inflammatory cytokine IL-6 was found to be overexpressed in chronic blepharitis [52].

In rabbit lipid biomarker studies, Nicolaides et al. produced a clinically evident meibomian gland deficiency model by daily topical application of $2 \%$ epinephrine for a period of 6 months-1 year [53]. Over time, the rabbit model resembled meibomian gland deficiency or chronic posterior blepharitis in humans. In this animal model, the content of both free sterols and ceramides were increased compared with those of normal controls. In a study comparing meibomian gland lipids of patients with chronic blepharitis, Shine and McCulley observed that the expression of polar lipids phosphatidylethanolamine and sphingomyelin was significantly reduced in patients with chronic blepharitis in conjunction with keratoconjunctivitis sicca, compared to individuals with chronic blepharitis and non-keratoconjunctivitis sicca-like symptoms [23]. Polar lipids, such as sphingomyelin and phosphatidylethanolamine are zwitterionic phospholipids that have been suggested to play a significant role in maintaining the interfacial layer between the aqueous and oil layers of the tear film. Foulks et al. [54] suggested that the ordering of lipid molecules is altered in meibomian gland dysfunction and azithromycin can improve the abnormal condition in a manner that correlates with clinical response to therapy.

\section{Biomarkers for conjunctivochalasis}

Conjunctivochalasis, defined as a redundant, loose, nonedematous inferior bulbar conjunctiva interposed between the globe and the lower eyelid, has been shown to cause different types of ocular surface irritation [55]. This disorder is a frequent cause of chronic ocular discomfort, such as irritation, epiphora, dryness, and blurred vision, and it generally affects elderly people. Although several reports regarding the etiology of conjunctivochalasis have been published, there continues to be a discrepancy between a theory that emphasizes aging and ocular movement and a theory that emphasizes ocular surface inflammation and delayed tear clearance as etiological factors. Several investigators have found potential tear biomarkers for conjunctivochalasis Table 6. Twenty-four proteins were significantly upregulated in conjunctivochalasis compared with controls [56]. Eleven proteins were identified, which included proteins belonging to the S100 family (A8, A9, A4; 2.44, 1.71, and 2.82 fold upregulation, respectively), guanosine triphosphate-binding protein 2 (1.95 fold), L-lactate dehydrogenase A-like $6 \mathrm{~B}$ ( 2.32 fold), fatty acid-binding protein ( 2.01 fold), keratin type I cytoskeletal 10 (1.81 fold), glutathione S-transpherase P (2.27 fold), peroxiredoxin-1, peroxiredoxin-5 (1.79 and 1.92 fold, respectively), and cullin- $4 \mathrm{~B}^{+}$glyceraldehyde 3-phosphate dehydrogenase (1.96 fold). Moreover, inflammatory cytokines IL- $1 \beta$ and IL- 6 were found to be overexpressed in conjunctivochalasis [52].

\section{Conclusions}

While some potential biomarkers for ocular diseases have been reported, it is difficult to select a single most important biomarker for each ocular disease. Some of the reviewed biomarker studies were conducted on small sample subgroups; newer analysis techniques may result in different and more specific findings. While progress has been made in developing various omics studies, studies comparing normal and diseased eye tears are still lacking. Preliminary studies suggest the importance of further research targeted at identifying potential ocular-associated lipid and non-lipid/protein biomarkers and protein biomarkers.

In dry eye and conjunctivochalasis, upregulation of S100 family proteins has been identified. S100 family proteins are markers of inflammation and oxidative processes, and monitoring their levels in tears might be useful for assessing the severity and progression ocular diseases. In dry eye, down-regulation of proline-rich proteins has been identified. Some cytokines may be upregulated in inflammatory eye conditions. Combining several of the potential biomarkers may be a good strategy for diagnosis and assessment of ocular diseases.

\section{References}

1. Holly FJ, Lemp MA (1977) Tear physiology and dry eyes. Surv Ophthalmol 22: $69-87$

2. Shine WE, McCulley JP (1998) Keratoconjunctivitis sicca associated with meibomian secretion polar lipid abnormality. Arch Ophthalmol 116: 849-852.

3. Snyder C, Fullard RJ (1991) Clinical profiles of non-dry eye patients and correlations with tear protein levels. Int Ophthalmol 15: 383-389.

4. Prydal JI, Artal P, Woon H, Campbell FW (1992) Study of human precorneal 
tear film thickness and structure using laser interferometry. Invest Ophthalmol Vis Sci 33: 2006-2011.

5. Redl B (2000) Human tear lipocalin. Biochim Biophys Acta 1482: 241-248.

6. Lehrer RI, Xu G, Abduragimov A, Dinh NN, Qu XD, et al. (1998) Lipophilin, a novel heterodimeric protein of human tears. FEBS Lett 432: 163-167.

7. Tomosugi N, Kitagawa K, Takahashi N, Sugai S, Ishikawa I (2005) Diagnostic potential of tear proteomic patterns in Sjogren's syndrome. J Proteome Res 4 : 820-825

8. Koo BS, Lee DY, Ha HS, Kim JC, Kim CW (2005) Comparative analysis of the tear protein expression in blepharitis patients using two-dimensional electrophoresis. J Proteome Res 4: 719-724.

9. Ohashi Y, Ishida R, Kojima T, Goto E, Matsumoto Y, et al. (2003) Abnormal protein profiles in tears with dry eye syndrome. Am J Ophthalmol 136: 291-299.

10. Grus FH, Podust VN, Bruns K, Lackner K, Fu S, et al. (2005) SELDI-TOFMS Protein Chip Array profiling of tears from patients with dry eye. Invest Ophthalmol Vis Sci 46: 863-876.

11. Zhou L, Huang LQ, Beuerman RW, Grigg ME, Li SF, et al. (2004) Proteomic analysis of human tears: defensin expression after ocular surface surgery. J Proteome Res 3: 410-416.

12. Molloy MP, Bolis S, Herbert BR, Ou K, Tyler MI, et al. (1997) Establishment of the human reflex tear two-dimensional polyacrylamide gel electrophoresis reference map: new proteins potential diagnostic value. Electrophoresis 18 2811-2815.

13. Grus FH, Augustin AJ (2001) High performance liquid chromatography analysis of tear protein patterns in diabetic and non-diabetic dry-eye patients. Eur $J$ Ophthalmol 11: 19-24.

14. Zhou L, Beuerman RW, Barathi A, Tan D (2003) Analysis of rabbit tear proteins by high-pressure liquid chromatography/electrospray ionization mass spectrometry. Rapid Commun Mass Spectrom 17: 401-412.

15. Fung KY, Morris C, Sathe S, Sack R, Duncan MW (2004) Characterization of the in vivo forms of lacrimal-specific proline-rich proteins in human tear fluid. Proteomics 4: 3953-3959.

16. de Souza GA, Godoy LM, Mann M (2006) Identification of 491 proteins in the tear fluid proteome reveals a large number of proteases and protease inhibitors. Genome Biol 7: R72.

17. Enriquez-de-Salamanca A, Castellanos E, Stern ME, Fernandez I, Ester Carreno E, et al. (2010) Tear cytokine and chemokine analysis and clinical correlations in evaporative-type dry eye disease. Mol Vis 16: 862-873.

18. Azzarolo AM, Brew K, Kota S, Ponomareva O, Schwartz J, et al. (2004) Presence of tear lipocalin and other major proteins in lacrimal fluid of rabbits. Comp Biochem Physiol B Biochem Mol Biol 138: 111-117.

19. Tsai PS, Evans JE, Green KM, Sullivan RM, Schaumberg DA, et al. (2006) Proteomic analysis of human meibomian gland secretions. $\mathrm{Br} \mathrm{J}$ Ophthalmol 90: $372-377$

20. McCulley JP, Shine WE (2003) Meibomian gland function and the tear lipid layer. Ocul Surf 1: 97-106.

21. Butovich IA, Millar TJ, Ham BM (2008) Understanding and analyzing meibomian lipids--a review. Curr Eye Res 33: 405-420.

22. McCulley JP, Shine WE (2001) The lipid layer: the outer surface of the ocular surface tear film. Bioscience Reports 21: 407-418.

23. Shine WE, McCulley JP (1998) Keratoconjunctivitis sicca associated with meibomian secretion polar lipid abnormality. Arch Ophthalmol 116: 849-852.

24. Mathers WD (1993) Ocular evaporation in meibomian gland dysfunction and dry eye. Ophthalmology 100: 347-351.

25. Greiner JV, Glonek T, Korb DR, Booth R, Leahy AD (1996) Phospholipids in meibomian gland secretion. Ophthalmic Res 28: 44-49.

26. Wollensak G, Mur E, Mayr A, Baier G, Göttinger W, et al. (1990) Effective methods for the investigation of human tear film proteins and lipids. Graefes Arch Clin Exp Ophthalmol 228: 78-82.

27. Sullivan BD, Evans JE, Krenzer KL, Dana MR, Sullivan DA (2000) Impact of antiandrogen treatment on the fatty acid profile of neutral lipids in human meibomian gland secretion. J Clin Endocrinol Metab 85: 4866-4873.
28. Jacob JT, Ham B (2008) Compositional profiling and biomarker identification of the tear film. Ocul Surf 6: 175-185.

29. Fujikawa LS, Foster CS, Harrist TJ, Lanigan JM, Colvin RB (1981) Fibronectin in healing rabbit corneal wounds. Lab Invest 45: 120-129.

30. Csutak A, Tözsér J, Békési L, Hassan Z, Berta A, et al. (2000) Plasminogen activator activity in tears after excimer laser photorefractive keratectomy. Invest Ophthalmol Vis Sci 41: 3743-3747.

31. Holopainen JM, Moilanen JAO, Sorsa T, Kivelä-Rajamäki M, Tervahartiala T, et al. (2003) Activation of matrix metalloproteinase-8 by membrane type 1-MMP and their expression in human tears after photorefractive keratectomy. Invest Ophthalmol Vis Sci 44: 2550-2556.

32. Murphy CJ, Marfurt CF, Mcdermott A, Bentley E, Abrams GA, et al. (2001) Spontaneous chronic corneal epithelial defects (SCCED) in dogs: clinical features, innervation, and effect of topical SP, with or without IGF-1. Invest Ophthalmol Vis Sci 42: 2252-2261.

33. Mikulec AA, Tanelian DL (1996) CGRP increases the rate of corneal reepithelialization in an in vitro whole mount preparation. J Ocul Pharmacol Ther 12: 417-423.

34. Lohmann CP, Hoffmann E, Reischi U (1998) Epidermal growth factor in the tear fluid: responsible for postoperative refraction and "haze"? Ophthalmologe 95: 80-87.

35. Vesaluoma M, Teppo AM, Grönhagen-Riska C, Tervo T (1997) Release of TGF- $\beta 1$ and VEGF in tears following photorefractive keratectomy. Curr Eye Res 16: 19-25.

36. Vesaluoma M, Teppo A, Grönhagen-Riska C, Tervo T (1997) Platelet-derived growth factor-BB (PDGF-BB) in tear fluid: a potential modulator of corneal wound healing following photorefractive keratectomy. Curr Eye Res 16: 825831.

37. Grierson I, Heathcote L, Hiscott P, Hogg P, Briggs M, et al. (2000) Hepatocyte growth factor/scatter factor in the eye. Prog Retin Eye Res 19: 779-802.

38. van Setten GB (1996) Basic fibroblast growth factor in human tear fluid: detection of another growth factor. Graefes Arch Clin Exp Ophthalmol 234 275-277.

39. Vesaluoma M, Teppo A, Grönhagen-Riska C, Tervo T (1997) Increased release of tumor necrosis factor- $\alpha$ in human tear fluid after excimer laser induced corneal wound. Br J Ophthalmol 81: 145-149.

40. Malecaze F, Simorre V, Chollet P, Tack JL, Muraine M, et al. (1997) Interleukin-6 in tear fluid after photorefractive keratectomy and its effects on keratocytes in culture. Cornea 16: 580-587.

41. Zhou L, Beuerman RW, Huang L, Barathi A, Foo YH, et al. (2007) Proteomic analysis of rabbit tear fluid: defensin levels after an experimental corneal wound are correlated to wound closure. Proteomics 7: 3194-3206.

42. Zhou L, Huang LQ, Beuerman RW, Grigg ME, Li SFY, et al. (2004) Proteomic analysis of human tears: defensin expression after ocular surface surgery. J Proteome Res 3: 410-416.

43. Lemp MA (1995) Report of the National Eye Institute/Industry workshop on clinical trials in dry eyes. CLAO J 21: 221-232.

44. Zhou L, Beuerman RW, Chan CM, Zhao SZ, Li XR, et al. (2009) Identification of tear fluid biomarkers in dry eye syndrome using iTRAQ quantitative proteomics. J Proteome Res 8: 4889-4905.

45. Saijyothi AV, Angayarkanni N, Syama C, Utpal T, Shweta A, et al. (2010) Two dimensional electrophoretic analysis of human tears: collection method in dry eye syndrome. Electrophoresis 31: 3420-3427.

46. Ham BM, Jacob JT, Keese MM, Cole RB (2004) Identification, quantification and comparison of major non-polar lipids in normal and dry eye tear lipidomes by electrospray tandem mass spectrometry. J Mass Spectrom 39: 1321-1336.

47. Ham BM, Cole RB, Jacob JT (2006) Identification and comparison of the polar phospholipids in normal and dry eye rabbit tears by MALDI-TOF mass spectrometry. Invest Ophthalmol Vis Sci 47: 3330-3338.

48. Sullivan BD, Evans JE, Dana MR, Sullivan DA (2006) Influence of aging on the polar and neutral lipid profiles in human meibomian gland secretions. Arch Ophthalmol 124: 1286-1292. 
49. Peral A, Carracedo G, Acosta MC, Gallar J, Pintor J (2006) Increased levels of diadenosine polyphosphates in dry eye. Invest Ophthalmol Vis Sci 47: 40534058.

50. Suzuki M, Massingale ML, Ye F, Godbold J, Elfassy T, et al. (2010) Tear osmolarity as a biomarker for dry eye disease severity. Invest Ophthalmol Vis Sci 51: 4557-4561.

51. MuCulley JP, Shine WE (2000) Changing concepts in the diagnosis and management of blepharitis. Cornea 19: 650-658.

52. Acera A, Rocha G, Vecino E, Lema I, Durán JA (2008) Inflammatory markers in tears of patients with ocular surface disease. Ophthalmic Res 40: 315-321.

53. Nicolaides N, Santos EC, Smith RE, Jester JV (1989) Meibomian gland dysfunction. III. Meibomian gland lipids. Invest Ophthalmol Vis Sci 30: 946-951.

54. Foulks GN, Borchman D, Yappert M, Kim SH, McKay JW (2010) Topical azithromycin therapy for meibomian gland dysfunction: clinical response and lipid alterations. Cornea 29: 781-788.
55. Meller D, Tseng SC (1998) Conjunctivochalasis: literature review and possible pathophysiology. Surv Ophthalmol 43: 225-232.

56. Acera A, Suárez T, Rodriguez-Agirretxe I, Vecino E, Durán JA (2011) Changes in tear protein profile in patients with conjunctivochalasis. Cornea 30: 42-49.

57. Ma P, Wang N, McKown RL, Raab RW, Laurie GW (2008) Focus on molecules: lacritin. Exp Eye Res 86: 457-458

58. Wojnar P, Dirnhofer S, Ladurner P, Berger P, Redl B (2002) Human lipocalin-1, a physiological scavenger of lipophilic compounds, is produced by corticotrophs of the pituitary gland. J Histochem Cytochem 50: 433-435.

59. Ham BM, Jacob JT, Cole RB (2007) Single eye analysis and contralateral eye comparison of tear proteins in normal and dry eye model rabbits by MALDI-ToF mass spectrometry using wax-coated target plates. Anal Bioanal Chem 387 889-900.

60. Chotikavanich S, de Paiva CS, Li DQ, Chen JJ, Bian F, et al. (2009) Production and activity of matrix metalloproteinase-9 on the ocular surface increase in dysfunctional tear syndrome. Invest Ophthalmol Vis Sci 50: 3203-3209. 